\title{
Diagnostic Dilemma of Subungual Glomus Tumor of Great Toe: A Case Report and Review of the Literature
}

\author{
Anjul Verma ${ }^{1}$, Rakesh Parmar ${ }^{2}$, Inder Pawar ${ }^{3}$, Shashank Agarwal ${ }^{4}$
}

\begin{abstract}
Background: Glomus tumor is a benign neoplasm also known as angioneuromyoma, arising from glomus bodies which are specialized structures for thermoregulation. ${ }^{1}$ Solitary benign glomus tumors are small, usually $<1.0 \mathrm{~cm}$ in size and they pose a diagnostic dilemma. ${ }^{2,3}$ They usually present with a classical triad of spontaneous pain, pressure tenderness, and cold hypersensitivity.

Case description: A 37-year-old woman presented to us with complaints of pain and temperature sensitivity, in left great toe with difficulty in wearing shoes from the last 5 years. X-rays and blood investigations were normal. Magnetic resonance imaging (MRI) was done and showed T1 hypointense, T2 hyperintensity, and subtle bone expansion with the possibility of glomus tumor. En bloc removal of the lesion was done and a histopathological report confirmed it to be a glomus tumor. The patient was asymptomatic after 3 weeks of surgery.

Discussion: The purpose of this case report is to make the orthopedic surgeon aware of the possibility of glomus tumor as a differential of chronic toe pain.

Keywords: Classical triad, En Bloc, Glomus tumor.

Journal of Foot and Ankle Surgery (Asia Pacific) (2022): 10.5005/jp-journals-10040-1145
\end{abstract}

\section{INTRODUCTION}

Glomus tumor is a benign neoplasm, arising from neuromyoarterial apparatus called glomus bodies which are specialized structures for thermoregulation. ${ }^{4}$ Glomus bodies are arteriovenous shunts surrounded by glomus cells, which contract via sympathetic activity, to regulate blood flow to the extremities. Glomus bodies are located in the dermis but more densely in apical skin areas, primarily the fingertips, followed by the base of the foot and the rest of the body. Glomus tumor has been reported at body sites, such as, head, neck, colon, lung, tongue, stomach, ear, elbow, wrist, hand, foot, toes, bladder, patella, coccyx, rectum, penis, and cervix. ${ }^{5}$ Glomus tumors are most commonly found in the extremities, with up to $75 \%$ of the presentations diagnosed in the hand and $90 \%$ of the hand lesions are located in the subungual tissues of the fingers. ${ }^{6}$

Foot glomus tumors are relatively rare due to the lower concentration of glomus bodies in the foot (i.e., even in the subungual region of the toes). ${ }^{7}$ Due to the low incidence of foot glomus tumors and variable clinical presentations, delayed diagnosis is frequent. ${ }^{8-10}$ In the foot, a clinical presentation has been reportedly confused with Morton's neuroma, flexor hallucis longus tendon injury, plexiform neurofibroma, and an ingrown toenail. ${ }^{11-14}$

Glomus tumor occurrences have been reported mostly in females during the third through fifth decades of life, though, the lesion may occur at any age. A glomus tumor most commonly presents as a small solitary blue or purple nodular subungual lesion clinically. ${ }^{15}$ Patients usually present with the classical triad of spontaneous pain, pressure tenderness, and hypersensitivity to cold. ${ }^{16}$ Majority of the lesions are solitary but multifocal involvement can occur and is seen in cases of neurofibromatosis type I. Sometimes the history of trauma in past may be present.

Despite advances in imaging capabilities, histopathological examination of the excised tumor is absolutely necessary to provide a definitive diagnosis. ${ }^{2}$ Microscopically, the lesion shows uniform epithelial cells distributed outside a branching vasculature with pink cytoplasm and centrally placed nuclei (Figs 1 to 8).

\footnotetext{
${ }^{1-3}$ Department of Orthopaedics, ESI-Postgraduate Institute of Medical Sciences and Research, New Delhi, India

${ }^{4}$ Department of Orthopaedics, Kalpana Chawla Government Medical College, Karnal, Haryana, India
}

Corresponding Author: Anjul Verma, Department of Orthopaedics, ESI-Postgraduate Institute of Medical Sciences and Research, New Delhi, India, Phone: +919953937211, e-mail: vermaanjul08@gmail. com

How to cite this article: Verma A, Parmar R, Pawar l, et al. Diagnostic Dilemma of Subungual Glomus Tumor of Great Toe: A Case Report and Review of the Literature. J Foot Ankle Surg (Asia Pacific) 2022;9(1):35-39. Source of support: Nil

Conflict of interest: None

Treatment is mainly surgically requiring complete excision of the lesion. Despite the relative rarity of this entity, one must be aware of the possibility of glomus tumor when a patient presents with persistent pain around his or her nail bed and has experienced previous unsuccessful surgery for pain. ${ }^{17}$ We believe that reporting this case may help to fill lacunae in clinical knowledge related to glomus tumors and help orthopedicians to keep this in mind while dealing with such cases.

\section{Case Description}

A 37-year-old woman presented in the outpatient department with complaints of pain and temperature sensitivity, in her left great toe with difficulty in wearing shoes for the last 5 years. The pain was acute in onset, spontaneous, paroxysmal, sharp, and worsened upon exposure to cold weather. The patient had consulted a dermatologist and a general surgeon and was managed with analgesics and partial nail plate removal and antibiotics but had no improvement. There was no history of trauma, similar swelling elsewhere, fever, diabetes mellitus, hypertension, and pulmonary tuberculosis. 


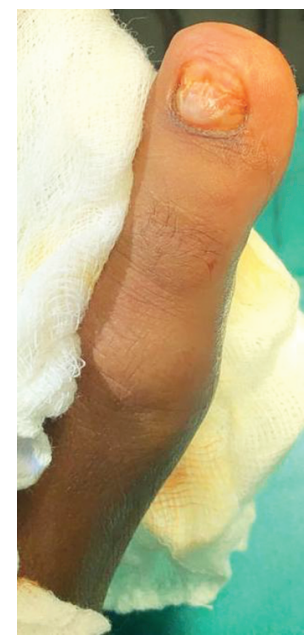

Fig. 1: Preoperative

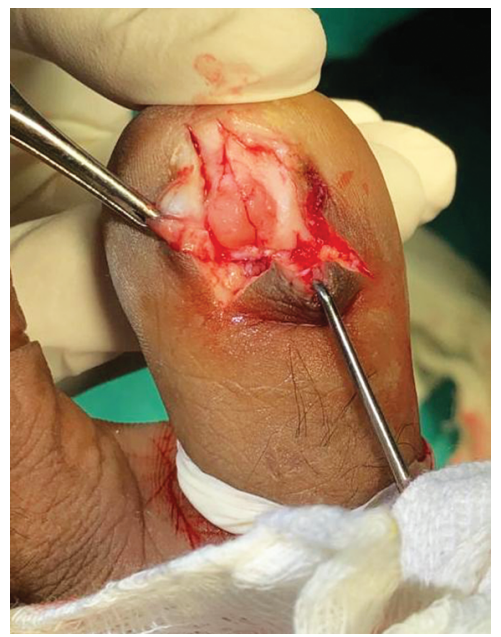

Fig. 3: Intraoperative

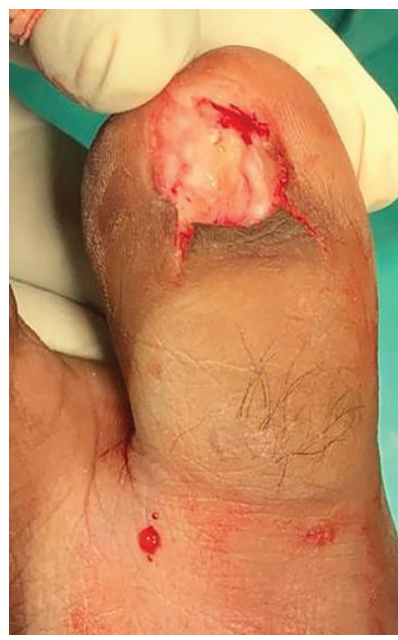

Fig. 5: Postoperative

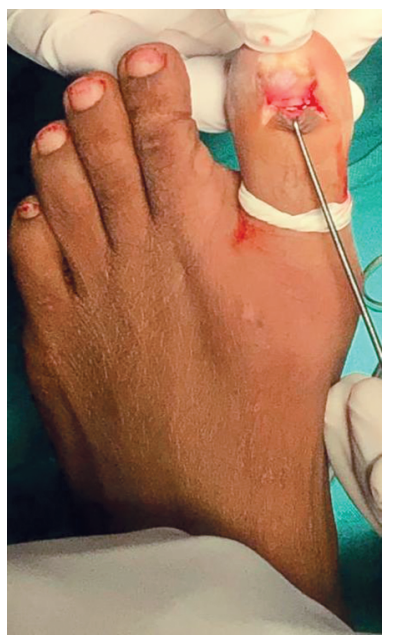

Fig. 2: Intraoperative

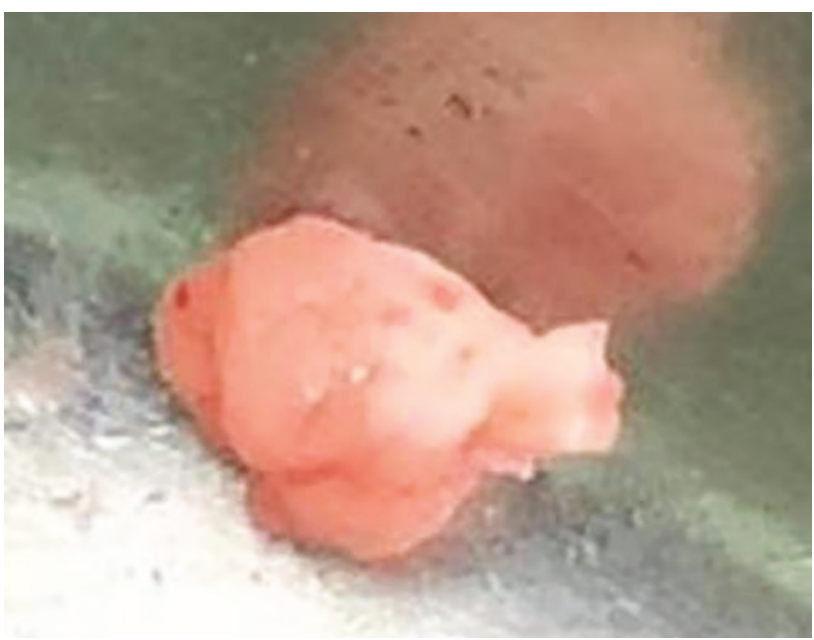

Fig. 4: Biopsy sample

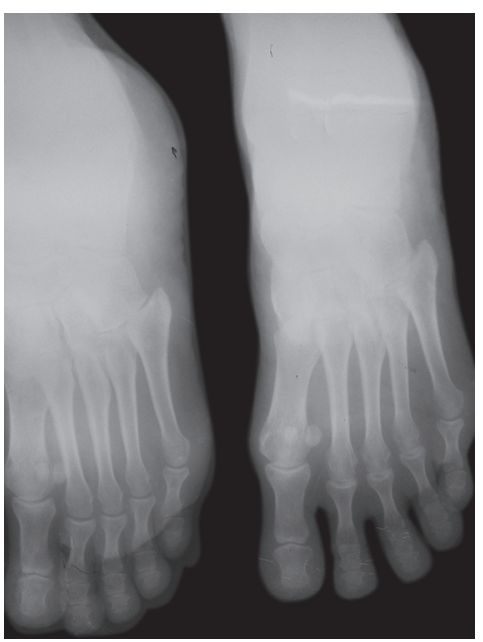

Fig. 6: X-ray foot-anteroposterior and oblique view 


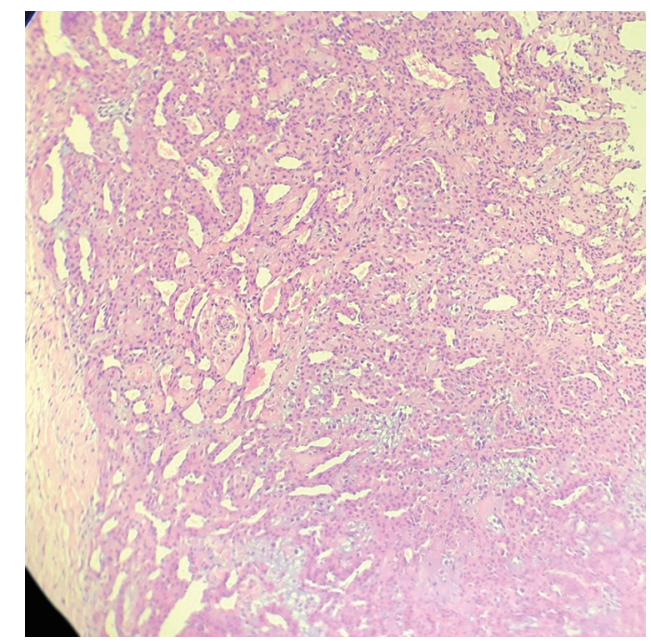

Fig. 7: $\mathrm{H}$ and $\mathrm{E}$ stained tissue showing glomus cells

Examination revealed subungual swelling of $0.8 \times 1 \mathrm{~cm}$ over left great toe. Severe point tenderness was present directly over the nail plate with partial cicatrization of the nail plate. There were no trophic changes or sinuses seen. A provisional diagnosis of glomus tumor was made.

The plain radiograph showed no features of soft tissue or bony involvement. Hemoglobin ( $\mathrm{Hb}$ ) was $11.2 \mathrm{~g} / \mathrm{dL}$, white blood cell (WBC) was 6,500 $\mu \mathrm{L}$, erythrocyte sedimentation rate (ESR) was $12 \mathrm{~mm} /$ hour, C-reactive protein (CRP) was negative, fasting blood sugar was $70 \mathrm{mg} / \mathrm{dL}$ were done and found to be within normal limits. Magnetic resonance imaging (MRI) was done and showed $\mathrm{T} 1$ hypointense, T2 hyperintensity, and subtle bone expansion with the possibility of glomus tumor.

Written and informed consent was taken, and the patient was prepared for removal of the lesion under regional anesthesia (ring block).

The lesion was excised En Bloc after removing the nail plate. Grossly lesion was $0.8 \times 1 \mathrm{~cm}$ in size, pale pink, well-capsulated, soft, and fleshy without signs of invasion to surrounding tissues. Removed tissue was sent for histopathological examination and diagnosis was confirmed on the report. The patient had disappearance of her symptoms by a week and became asymptomatic after 3 weeks of surgery without any complications. She has been under regular follow-up in the orthopedics outpatient department for 1 year.

\section{Discussion and Review of Literature}

Glomus tumor is a benign neoplasm arising from neuromyoarterial apparatus called a glomus body. Glomus bodies are arteriovenous shunts, surrounded by glomus cells, which contract to regulate blood flow to the extremities. Hence, they play a role in thermoregulation.

The most common site of occurrence of this tumor is the subungual area of the fingers and sometimes in the toes. The glomus tumor was first mentioned by Wood in $1812^{18}$ but a complete description of its character was given by Masson in $1924 .{ }^{19}$ It accounts for $<2 \%$ of soft tissue tumors. ${ }^{20}$ The initiating, or causative, event associated with glomus cell proliferation and eventual glomus tumor formation is unknown. Once established, glomus tumors are typically composed of three components: glomus cells, vessels, and smooth muscle cells. According to the proportion of these three components, glomus tumors can

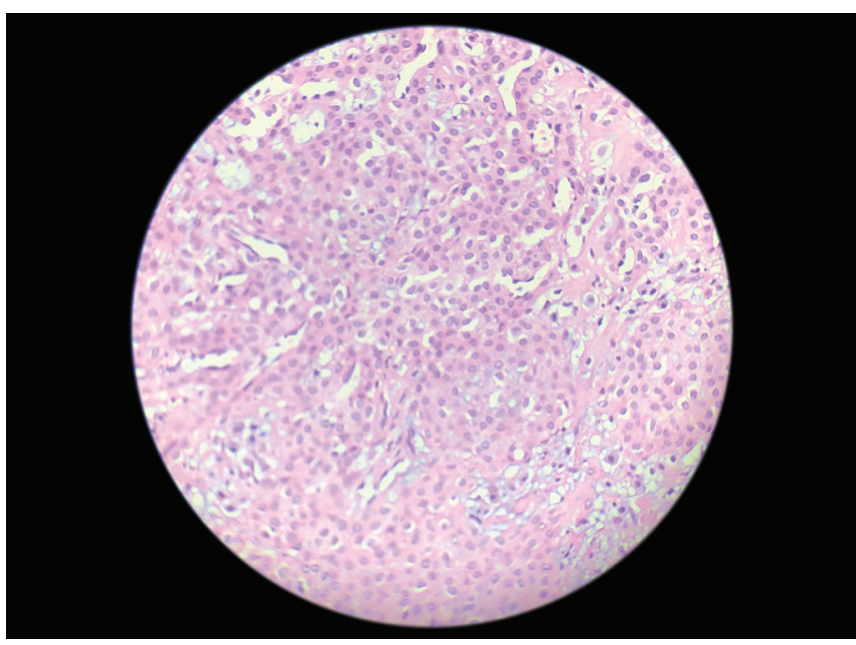

Fig. 8: Well-circumscribed lesion consisting of sheets and trabeculae of glomus cell surrounded by branching capillary sized as well as dilated blood vessels in a myxoid stroma. The cells are round with eosinophilic cytoplasm and round, sharply punched out nucleus with homogeneous chromatin and inconspicuous nucleoli

be subcategorized as solid glomus tumors, glomangioma, or glomangiomyoma. Solid glomus tumor is the most common variant (75\%), followed by glomangioma (20\%) and glomangiomyoma $(5 \%){ }^{20}$ The diagnosis is essentially clinical which is usually confirmed on histopathology with surgical excision.

This case showed that glomus tumors are very painful tumors and are challenging to diagnose and often the patient is misdiagnosed between different departments. Clinical examinations may include the Hildreth test and the Love test. The Hildreth test is highly specific and sensitive due to the vascular nature of the lesion. A positive Love test consists of pain on pressure directly over the symptomatic lesion. ${ }^{10}$ Differential diagnoses include ganglion cyst, hiradenomas, neuroma, angioma, melanoma, myxoid cyst, ${ }^{2}$ melanoma, chronic paronychia, gout arthritis, and foreign-body granuloma.

Imaging modalities used in the diagnosis of a glomus cell tumor include plain film radiography, color Doppler ultrasonography, computed tomography, angiography, and MRI. ${ }^{21}$

Some patients give a history of preceding trauma for which they are managed for subungual hematoma and some are taking analgesic and antidepressant medications for chronic paronychia for many years. However, with proper history, examination, and investigations (MRI), the tumor can be diagnosed early and timely managed.

About $75 \%$ of glomus tumors will arise in the hands, with $75-90 \%$ of these in subungual locations. ${ }^{16}$ Glomus tumors have been categorized into solitary and multiple types. Most have been solitary, with up to $25 \%$ of the multiple types. ${ }^{22,23}$ Solitary glomus tumors will be encapsulated, will usually be found in subungual locations, and will contain numerous small vascular lamina. ${ }^{24}$ In contrast, multiple type tumors will be unencapsulated, will rarely be subungual, will have larger shaped vascular spaces, and will often be asymptomatic. ${ }^{25}$ Glomus tumors have been more common in females than in males and have been the most prevalent during the fourth decade of life. ${ }^{16,26}$

About $1 \%$ of all glomus tumors are malignant. ${ }^{11}$ The malignant histopathological features include large size $(2 \mathrm{~cm})$ and deep location, or moderate-to-high nuclear grade and increased mitotic 
Table 1: Summarized descriptions of glomus tumors of toes given by different authors

\begin{tabular}{|c|c|c|c|c|c|c|}
\hline S. no. & Author/year & Age/sex & Presentation & Diagnostic issues & $\begin{array}{l}\text { Confirmation of diag- } \\
\text { nosis }\end{array}$ & Management \\
\hline 1. & Koti et al. ${ }^{33} 2001$ & $31 / \mathrm{F}$ & $\begin{array}{l}\text { Intermittent pain over the base of } \\
\text { the nail bed of the right hallux }\end{array}$ & $\begin{array}{l}\text { Several year his- } \\
\text { tories }\end{array}$ & MRI, histopathological & Excision \\
\hline 2. & $\begin{array}{l}\text { Pater and Marks } \\
2004\end{array}$ & $28 / \mathrm{F}$ & Lateral nail pain over left hallux & Ingrown toenail & MRI, histopathological & Excision \\
\hline 3. & Seo et al. ${ }^{34} 2014$ & $30 / \mathrm{F}$ & Pain in her right hallux & $\begin{array}{l}\text { Inflammation or } \\
\text { edema of the nail } \\
\text { bed }\end{array}$ & MRI, histopathological & Excision \\
\hline 4. & Lui and Mak ${ }^{10} 2014$ & $41 / \mathrm{F}$ & $\begin{array}{l}\text { Tiny lump and pain at her left } \\
\text { great toe pulp }\end{array}$ & $\begin{array}{l}\text { Neuroma, heman- } \\
\text { gioma }\end{array}$ & MRI, histopathological & Excision \\
\hline 5. & $\begin{array}{l}\text { Mohindra et al. }{ }^{1} \\
2016\end{array}$ & $19 / \mathrm{F}$ & Bursting pain in the left great toe & $\begin{array}{l}\text { Pain since past } 8 \\
\text { years }\end{array}$ & MRI, histopathological & Excision \\
\hline 6. & Current report & $37 / F$ & $\begin{array}{l}\text { Bursting pain and temperature } \\
\text { sensitivity in left great toe with } \\
\text { difficulty in wearing shoes }\end{array}$ & $\begin{array}{l}\text { Chronic paronych- } \\
\text { ia, ingrown toe } \\
\text { from last } 5 \text { years }\end{array}$ & MRI, histopathological & Excision \\
\hline
\end{tabular}

rate $(5 / 50$ high power fields), or the presence of atypical mitotic figures. If the histological criteria for malignancy are met, then the lesions are associated with more than a $25 \%$ risk of metastasis. ${ }^{27}$ However, tumors with some but not all of these ominous features (i.e., high mitotic activity and superficial location, large size only, or deep location only) are best described as glomus tumors with uncertain malignant potential, or symplastic glomus tumors (high nuclear grade only). ${ }^{28}$

A differential diagnosis should be carried out that considers the following possibilities: chronic paronychia, where a complete and detailed clinical history of the patient can serve to easily determine if this diagnosis is, in fact, the case; subungual melanoblastoma, which, unlike glomus tumors, is not usually painful; subungual hematoma, which is usually accompanied by a previous trauma and as a result could have been forgotten about; and other less frequent possibilities, such as, neuron, plexiform neurofibroma, papillomas, and fibromas. Last but not least, Koenen's tumors should also be taken into account since they appear as medial or lateral fleshy elongated proliferations that are located on the nail and closely joined to the matrix. ${ }^{29,30}$

Carroll and Berman ${ }^{16}$ have defined the classic triad of symptoms of glomus tumors as severe pain, point tenderness, and cold sensitivity, and these symptoms form the key to the diagnosis. However, not all glomus tumors will present with this classic triad of symptoms.

Van Geertruyden et al. ${ }^{31}$ have reported that in patients with solid glomus tumors, pain, point tenderness, and cold sensitivity will occur at a rate of 80,100 , and $63 \%$, respectively.

In Table 1, we have summarized descriptions of glomus tumors of toes given by different authors.

In conclusion, the diagnosis of foot glomus tumors requires clinical suspicion given its low incidence and wide differential diagnosis. Patients may have undergone prior surgeries as a result of misdiagnosis (most frequently an ingrown toenail). ${ }^{32}$

We believe that reporting this case may help to fill lacunae in general clinical knowledge related to glomus tumors and help clinicians. En Bloc excision of the tumor is a good modality of treatment. There is generally a delay in diagnosis and often the patient suffers great morbidity and having knowledge of this can help to reduce it.

\section{References}

1. Mohindra M, Sambandam B, Gautam VK, et al. A rare case of glomus tumor of the great toe: an analysis of Behavior at this rare site. Foot Ankle Spec 2016;9(1):83-87. DOI: 10.1177/1938640015578517.

2. Sprinkle 3rd RLB, Sangueza OP, Schwartz GA. Glomus tumor of the toe. J Am Podiatr Med Assoc 2017;107(3):257-260. DOI: 10.7547/15-161.

3. Gombos Z, Zhang PJ. Glomus tumor. Arch Pathol Lab Med 2008;132(9):1448-1452.

4. Gencoglan G, Dereli T, Kazandi AC. Subungual glomus tumor: surgical and histopathologic evaluation. Cutan Ocul Toxicol 2011;30(1):72-74. DOI: 10.3109/15569527.2010.521224.

5. Perivascular tumors. in: Enzinger FM, Weiss SW, ed. Enzinger and Weiss's Soft Tissue Tumors. 4th ed., Maryland Heights, MO: Mosby; 2001. p. 985.

6. Sapuan J, Paul AG, Abdullah S. Glomus tumor in the second toe: a clinical insight. J Foot Ankle Surg 2008;47(5):483-486. DOI: 10.1053/j. jfas.2008.05.008.

7. Strahan J, Bailie HW. Glomus tumour. A review of 15 clinical cases. $\mathrm{Br}$ J Surg 1972;59(2):91-93. DOI: 10.1002/bjs.1800590204.

8. Kreel L, Thornton A, Pardy BJ. Glomus tumour of the hallux: diagnosis by doppler-shift ultrasound and digital subtraction angiography. Postgrad Med J 1986;62(729):647-651. DOI: 10.1136/pgmj.62.729.647.

9. Luis LR, Kaoru GR, Shemuel PB, et al. Lower extremity glomus tumors: comprehensive review for surgeons. Vascular 2008;16(6):326-332. DOI: $10.2310 / 6670.2008 .00064$.

10. Lui TH, Mak SM. Glomus tumor of the great toe. J Foot Ankle Surg 2014;53(3):360-363. DOI: 10.1053/j.jfas.2013.05.011.

11. Miyano JA, Fitzgibbons TC. Glomangioma of the ankle simulating injury to the flexor hallucis longus: a case report. Foot Ankle Int 1996;17(12):768-770. DOI: 10.1177/107110079601701210.

12. Pater TJ, Marks RM. Glomus tumor of the hallux: case presentation and review of the literature. Foot Ankle Int 2004;25(6):434-437. DOI: 10.1177/107110070402500614.

13. Sun BG, Yun-tao W, Jia-zhen L. Glomus tumours of the hand and foot. Int Orthop 1996;20(6):339-341.

14. Tsuchie H, Okada K, Nagasawa $H$, et al. Glomus tumor of the toe with symptoms similar to those of Morton's disease. J Orthop Sci 2009;14(6):826-829. DOI: 10.1007/s00776-009-1387-y.

15. Assmus $\mathrm{H}$, Dombert T. Glomus tumours of the extremities: localisation and operative treatment in 36 cases. Handchir Mikrochir Plast Chir 2002;34(2):103-107. DOI: 10.1055/s-2002-32308.

16. Carroll RE, Berman AT. Glomus tumours of the hand: review of the literature and report on twenty-eight cases. J Bone Jt Surg Am 1972;54(4):691-703. DOI: 10.2106/00004623-197254040-00001. 
17. Horst F, Nunley JA. Technique tip: glomus tumors in the foot: a new surgical technique for removal. Foot Ankle Int 2003;24(12):949-951. DOI: $10.1177 / 107110070302401215$.

18. Wood W. On painful subcutaneous tubercle. Edinburg Med Surg J 1812;8(31):283-291.

19. Masson P. Le glomus neuromyoarterial des regions tactile et ses tumors. Lyon Chir 1924;21:257.

20. Pathology and Genetics of Tumours of the Nervous System, In Fletcher CDM, Unni K, Meretens F, ed. 1st ed., Lyon, France: IARC Press; 2002. pp 136-137.

21. Takemura N, Fujii N, Tanaka T. Subungual glomus tumor diagnosis based on imaging. J Dermatol 2006;33(6):389-393. DOI: 10.1111/j.13468138.2006.00092.x.

22. Maxwell GP, Curtis RM, Wilgis EF. Multiple digital glomus tumors. J Hand Surg 1979;4(4):363-367. DOI: 10.1016/S0363-5023(79) 80076-3.

23. McDermottEM, Weiss AP. Glomus tumors. JHand Surg 2006;31(8):13971400. DOI: 10.1016/j.jhsa.2006.05.018.

24. Drapé JL, Idy-Peretti I, Goettmann S, et al. Subungual glomus tumors: evaluation with MR imaging. Radiology 1995;195(2):507-515. DOI: 10.1148/radiology.195.2.7724775.

25. Moor EV, Goldberg I, Westreich M. Multiple glomus tumor: a case report and review of the literature. Ann Plast Surg 1999;43(4):436-438. DOI: 10.1097/00000637-199910000-00016.
26. Fleegler EJ, Zeinowicz RJ. Tumors of the perionychium. Hand Clin 1990;6(1):113-133. , discussion 135, 116.

27. Khoury T, Balos L, McGrath B, et al. Malignant glomus tumor: a case report and review of literature, focusing on its clinicopathological features and immunohistochemical profile. Am J Dermatopathol 2005;27(5):428-431. DOI: 10.1097/01.dad.0000148281.96494.d4.

28. Folpe AL, Fanburg-Smith JC, Miettinen M, et al. Atypical and malignant glomus tumors: analysis of 52 cases, with a proposal for the reclassification of glomus tumors. Am J Surg Pathol 2001;251(1):1-12. DOI: 10.1097/00000478-200101000-00001.

29. BaoGuo S, Yuntao W, Jiazhen L. Glomus tumors of the hand and foot. Int Orthopaedics 1996;20(6):339-341. DOI: 10.1007/s002640050092.

30. Coughlin M, Mann R, Saltzman ChL. Surg Foot Ankle 2007;14:750.

31. Van Geertruyden J, Lorea P, Goldschmidt D, et al. Glomus tumours of the hand: a retrospective study of 51 cases. J Hand Surg 1996;21(2):257-260. DOI: 10.1016/S0266-7681(96)80110-0.

32. Trehan SK, Soukup DS, Mintz DN, et al. Glomus tumors in the foot: case series. Foot Ankle Spec 2015;8(6):460-465. DOI: 10.1177/1938640015583514

33. Koti M, Bhattacharryya R, Ewen SWB, et al. Subungual glomus tumor of the hallux: a case report. Acta Orthop Belg 2001;67(3):297-299.

34. Seo JH, Lee HS, Kim SW, et al. Subungual glomus cell proliferation in the toe: a case report. J Foot Ankle Surg 2014;53(5):628-630. DOI: 10.1053/j.jfas.2014.03.004. 